\title{
COMUNICAÇ̃̃O E FEMINISMO: UM PANORAMA A PARTIR DA PRODUÇÃO DE TESES E DISSERTAÇ̃̃ES DO CAMPO DA COMUNICAÇ̃̃O ENTRE 2010 E 2015
}

\author{
COMMUNICATION AND FEMINISM: AN OVERVIEW FROM THE PRODUCTION \\ OF THESES AND DISSERTATIONS IN THE FIELD OF COMMUINICATION BETWEEN 2010 AND 2015
}

\section{RESUMO}

Nesse artigo, apresentamos um panorama de como o campo da Comunicação problematiza o feminismo. Para isso, analisamos algumas contribuições da área, a partir de um mapeamento de teses e dissertações dos programas de Pós-graduação em Comunicação no Brasil durante a primeira metade dos anos 2010. Ao todo, 21 pesquisas foram identificadas e analisadas a fim de explorar os temas que recebem maior atenção, além de outros dados inferidos sobre a produção.

Palavras-chave: Comunicação. Estudos de mídia. Feminismo. Pesquisa. Estado da arte.

\section{ABSTRACT}

In this article, is presented an overview of how the field of communication problematizes feminism. For this, some of the contributions of the area were analyzed, based on a mapping of theses and dissertations of the Brazilian graduate programs in Communication during the first half of 2010. In total, 21 researches were identified and analyzed in order to explore topics that receive more investment, as well as other inferred data on production.

Keywords: Communication. Media studies. Feminism. Research. State of art.

\section{Introdução}

O feminismo, entendido de maneira geral como corrente de pensamento que reivindica igualdade de direitos e oportunidades de gênero, volta a ocupar um lugar de destaque em discussões públicas, programas de televisão, revistas (principalmente as femininas), e seu impacto reverbera em múltiplas instâncias sociais. Depois de ser questionado nos anos 1990 e 2000 no mundo ocidental, especialmente após a ampliação do mercado de trabalho e sanção de leis que igualam direitos civis, o feminismo é retomado. Novas vozes passam, aos poucos, a (re)questionar o machismo e o patriarcado, um reflexo das estatísticas (e do cotidiano) que deixam claro que a igualdade está longe de ser alcançada.

Paula Coruja

Universidade Federal do Rio Grande do Sul (UFRGS). E-mail: paula.coruja@gmail.com 
Esse feminismo, (re)aparece agora com uma nova lógica, principalmente comunicacional (Tomazetti, 2015). Ressurge não apenas mais heterogêneo, mas difuso (Coruja, 2017). Notamos uma clara associação, principalmente por mulheres jovens, a valores gerais e reivindicações históricas conectados ao(s) feminismo(s), do que exatamente a correntes teóricas e/ou políticas. Assim, as discussões em torno de seu discurso, interseccionalidades, sujeitos, práticas, desafios e problematizações ganham também nova atenção do campo acadêmico, que, a partir das diversas disciplinas, tentam compreender esses fenômenos (e muitas vezes colaborar para uma ação transformadora).

Nesse artigo, traremos a discussão para o campo da Comunicação, analisando algumas contribuições da área, a partir da produção de teses e dissertações dos programas de Pós-graduação em Comunicação no Brasil durantea primeira metade dos anos 2010. A partir dessa produção vamos apontar aspectos teóricos, metodológicos, e objetos ancorados no feminismo que são problematizados pelo campo.

Esse tipo de pesquisa bibliográfica se encaixa nos chamados estados da arte, que procuram identificar tendências em um determinando campo de conhecimento a partir do mapeamento e discussão sobre a produção acadêmica em diferentes campos (Ferreira, 2002). Esses levantamentos são necessários para o "processo de evolução da ciência, a fim de que se ordene periodicamente os resultados obtidos” (Soares, 1987, p.3).

Antes de entrarmos na análise propriamente dita, vamos revisar alguns aspectos da trajetória dos estudos feministas que convergem com os estudos em comunicação, principalmente a partir dos Estudos Culturais, corrente teórica que têm sua trajetória intimamente ligada ao desenvolvimento dos estudos feministas nas décadas de 1960 e 1970. Dentro dessa seara, trazemos algumas contribuições brasileiras, a partir dos estudos de recepção e consumo midiático.

Por fim, apontamos os aspectos mais evidentes da maneira como as áreas se encontram a partir dos trabalhos, apontando avanços que podem servir para continuar problematizando essas questões.

\section{Estudos culturais e estudos feministas: uma aproximação}

A trajetória dos estudos feministas de mídia, principalmente, está intrinsecamente ligada à perspectiva dos estudos culturais britânicos, que nasce no final da década de 1950, a partir do pensamento de Richard Hoggart, Raymond Williams e Edward Thompson. Stuart Hall relata que o feminismo caracterizou um dos momentos de ruptura (ele usa a metáfora do ladrão que chega à noite e faz um barulho "inconveniente") do desenvolvimento dos estudos culturais e que convidou algumas feministas a integrarem o Centre for Contemporary Cultural Studies (CCCS) em Birmingham, pois os estudos culturais estariam "sensíveis à política feminista" (Hall, 2006, p.474). Porém, as feministas criticam a maneira como foram tratadas no CCCS e a descrição feita por Hall. Brundson (1996, p. 280) diz: 
Na primeira vez em que li essa avaliação, eu queria esquecêla imediatamente. Negá-la, ignorá-la, desconhecê-la - não reconhecer a agressão ali contida. Não tanto para negar que as feministas do CCCS, durante os anos 70, haviam feito um poderoso desafio aos estudos culturais, na forma como estavam constituídos naquele momento e naquele lugar, mas para negar que tivesse acontecido da forma ali descrita.

Entretanto as perspectivas tinham muitos pontos em comum: nasceram fora da academia, levam em conta contextos culturais, políticos e sociais, além de mudar o olhar para as minorias, "e foram alvos de críticas ao declarar não existir conceitos e teorias que dessem conta de seus objetos” (Messa, 20o8, p.41). O papel da mulher e a problematização da categoria de gênero, já na década de 1970, constituem uma das grandes contribuições dos estudos feministas aos estudos culturais e “(...) propiciou novos questionamentos em redor de questões referentes à identidade, pois introduziu novas formas variáveis na sua constituição, deixando de ver os processos de identidade unicamente através da cultura de classe e sua transmissão geracional” (Escosteguy, 2001, p.41). Tais pesquisas evidenciam não só a diferença de significados entre gêneros, mas como a desigualdade é produzida nos mais diversos produtos midiáticos.

A diferença de papéis de gênero, por exemplo, está presente na pesquisa de David Morley (1996) sobre os hábitos de famílias britânicas para assistir televisão em 1985. Dentro das discussões de gênero e feminismo, algumas autoras identificadas com os estudos culturais, mostraram essa desigualdade produzida e reproduzida através dos meios. Christine Geraghty (1998) demonstrou que muito da ideia sobre o que é ser mulher foi construída dentro do discurso cinematográfico e que a representação do que é feminino seria "uma fantasia dominada pelos homens" (Geraghty, 1998, p.465). Além disso, as identificações geradas através das personagens em novelas estão ligadas à estrutura patriarcal da sociedade. Os estudos de Mulvey (1999) sobre cinema apontam que o lugar que as mulheres ocupam nas produções hollywoodianas, com raras exceções, são construções feitas a partir de uma fantasia patriarcal. Angela McRobbie (1998), pontuou que as revistas femininas são o meio mais antigo de construção da feminilidade normativa e que, até pouco tempo, o discurso apresentado se concentrava em ditar regras sobre como ser bonita para os homens, e se tornar "irresistível" exclusivamente para eles, com uma publicidade que apresentava a mulher como um ser a disposição de ser "consumida" e que era sempre colocada em relação de "subordinação, passividade e disponibilidade sexual” (McRobbie, 1998, p.265). Um discurso que hoje é questionado através de práticas de contestação (Wottrich, 2017) em sites de redes sociais, um espaço que as audiências reivindicam para si para dar a sua versão, sua opinião e produzir os mais diversos materiais. 


\section{Feminismo e Comunicação: desenvolvimento crescente no Brasil}

No contexto brasileiro, as relações entre os estudos de mídia e os estudos de gênero, em sua maioria voltados a questões que concernem as mulheres, vêm se desenvolvendo nas últimas décadas. Escosteguy (2012) salienta que houve um descompasso entre o crescimento de estudos com a temática de gênero nas Ciências Sociais ea Comunicação até a década de 1990, quando começam a aparecer no Brasil. Para a pesquisadora, a dispersão da produção sobre gênero no Brasil é "característica que marca a pesquisa brasileira em comunicação" (Escosteguy, 2008, p.7), mas que a temática vem ganhando força. O inventário de teses e dissertações em programas de pós-graduação no Brasil de 1992 a 2002 capitaneado por Escosteguy (2008) mostra o esforço de colocar a questão em evidência e mostrar que a problematização junto ao campo da Comunicação é urgente.

Como também apontou a pesquisadora, os estudos de recepção em Comunicação foram os primeiros a dar atenção às mulheres, sempre preferenciais como sujeitos deste tipo de pesquisa. Escosteguy ${ }^{1}$ (2012, p.6), inclusive, diz que a "problemática da recepção, associada ao seu desenvolvimento dentro do âmbito dos estudos culturais, constituiu a motivação para o meu vínculo com as questões de gênero". Para Ronsini e Silva (2011, p. 2): "Entender a recepção sob a ótica do gênero pode nos ajudar a desvendar as conexões entre o consumo de bens midiáticos pelas mulheres e as constantes negociações de poder no interior das famílias". Por isso, a partir dos estudos de recepção, vemos um impulsionamento da discussão da temática dentro do campo feminista, mesmo que levantamentos apontem que muitas vezes nesses estudos as mulheres sejam os sujeitos preferenciais investigados, mas sua condição não seja problematizada (John, Costa, 2014; Tomazetti, Coruja, 2017).

Agora que temos um panorama mais amplo sobre como os caminhos dos estudos feministas e estudos em comunicação convergem, é hora de olhar para a produção mais atual da pós-graduação para compreender um pouco melhor como o campo da Comunicação no Brasil está o olhando/estudando essa temática.

\section{A produção da pós-graduação em Comunicação sobre feminismo: questão em ascensão}

Para entender como o campo da Comunicação está problematizando o feminismo atualmente, fomos em busca da produção acadêmica da área. Consultamos a base de dados levantada pelo Núcleo de Pesquisa Cultura e Recepção Midiática da UFRGS ${ }^{2}$, em busca de trabalhos traziam o feminismo citado no título e/ou resumo e/

1 Escosteguy esteve à frente de dois grandes projetos de pesquisa que problematizavam a questões relativas a gênero e/ou mulheres aprovados pelo CNPq: de 2001 a 2003 "Os Estudos Culturais e a problemática da recepção: A categoria gênero em debate” e, mais recentemente, de 2013 a 2015, "Mulheres e suas interações cotidianas com tecnologias de comunicação: o caso de jovens e adultas relacionadas à cadeia agroindustrial do tabaco".

2 Nos valemos do banco de dados levantado para uma pesquisa capitaneada pela professora Nilda Jacks 
ou palavras-chaves, entre os anos de 2010 e 2015. Ao todo, encontramos 21 trabalhos 3 , desses, sete teses e 14 dissertações.

Primeiramente, podemos destacar que houve um crescente interesse na temática, já que em 2010 tivemos apenas dois trabalhos defendidos, enquanto que em 2015 o número foi de 11 trabalhos, como é possível visualizar no gráfico abaixo (Figura 1).

Figura 1: Total de trabalhos que tratam ${ }^{4}$ sobre feminismo por ano

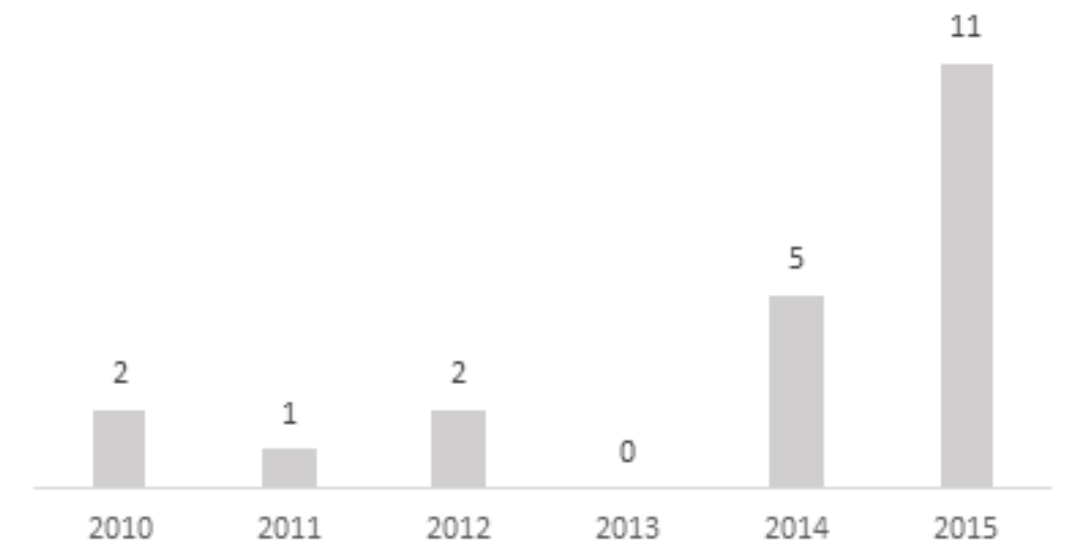

Se analisarmos a produção por região, vemos uma grande disparidade. Os estados do Sudeste lideram com 15 trabalhos defendidos no período, seguido pelo Nordeste, com quatro trabalhos, e o Sul, com dois. Norte e Centro-Oeste não apresentaram trabalhos que trouxessem o feminismo citado.

Quando analisamos por universidades (Figura 2), vemos que mesmo nas regiões de maior concentração da produção os trabalhos estão pulverizados, com a maioria das IES tendo apenas um trabalho que trazia essa abordagem. UFRJ e UFPE tiveram três trabalhos defendidos, PUC-SP, Anhembi Morumbi e Unicamp, dois, e o restante

no Núcleo de Pesquisa Cultura e Recepção Midiática na UFRGS, onde atuo, atualmente, como bolsista de apoio técnico. Em busca dos trabalhos de recepção desenvolvidos no Brasil no período de 20102015, a equipe levantou o total da produção de teses e dissertações no Brasil na área da Comunicação, formando uma base de dados valiosa para consulta. O resultado dessa pesquisa está registrado no livro "Meios e Audiências 3: a reconfiguração dos estudos de recepção e consumo midiático", a ser lançado pela Editora Sulina em setembro de 2017.

3 É importante salientar que quase não foi possível ter acesso a todos os trabalhos completos. As teses de Dantas (2015) e Leite (2015) e a dissertação de Araújo (2015) não estão disponíveis nos sites dos respectivos PPGs, nem no repositório das universidades. Por isso é de grande valia a iniciativa de disponibilizar na Plataforma Sucupira, além dos resumos, links para os pdfs das obras. Isso ajuda na construção de um banco de dados nacional e aberto. $\mathrm{O}$ único trabalho que não conseguimos ler na íntegra foi o de Andrade (2011), porque além de não estar disponível nos repositórios das universidades é anterior ao banco de dados do Sucupira.

4 Sabemos que alguns trabalhos podem não ter sido incluídos por não trazerem palavras-chaves relacionadas ao feminismo entre os itens principais disponíveis para busca. Isso desperta uma reflexão não somente no sentido de apontar limites para esta pesquisa, mas em salientar a importância da elaboração de resumos e títulos que deem conta de todos os aspectos considerados fundamentais nos trabalhos. Durante o estudo para esse artigo, encontramos diversos trabalhos que primavam pela criatividade na redação dos títulos, deixando de lado elementos fundamentais com relação à indexação, sem trazer informações relevantes sobre a problemática, aporte teórico, metodológico e resultados. 
apenas um. Isso nos mostra que não há nenhum programa, ou linha de pesquisa de referência que trate exclusivamente dessa temática na Comunicação5.

Figura 2: Produção por universidade

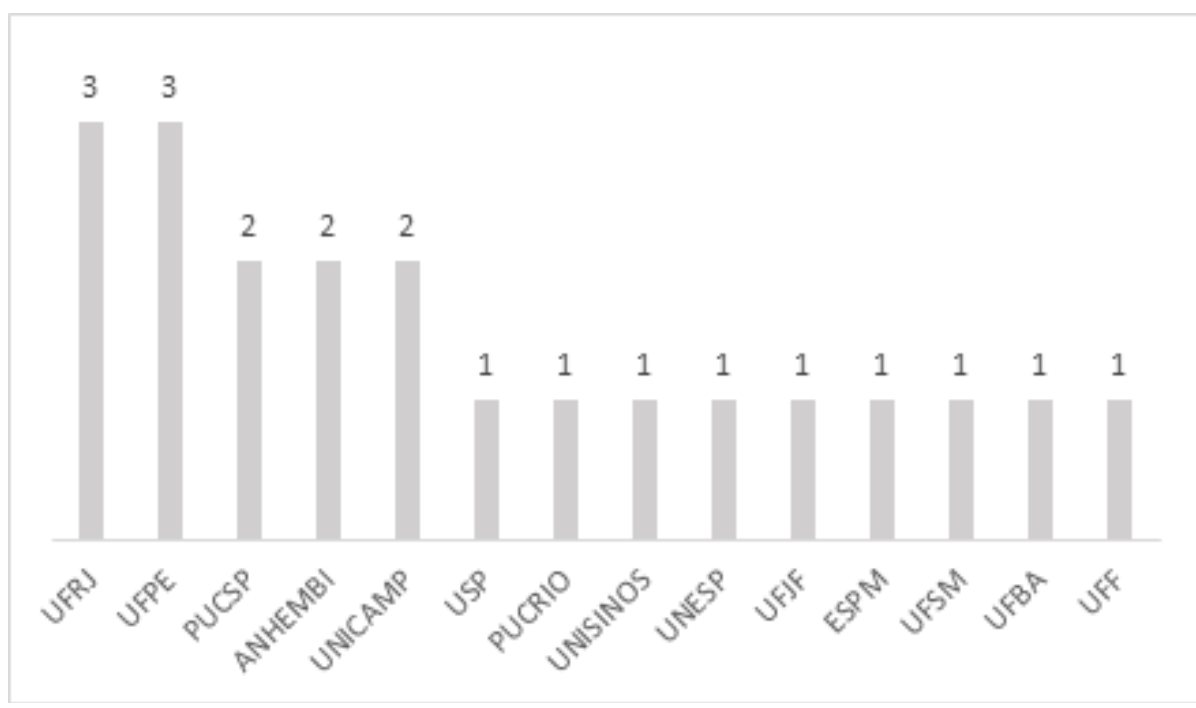

Se passarmos a olhar quem orienta os trabalhos, temos um equilíbrio, primeiramente, no próprio gênero dos orientadores, com 11 mulheres e 10 homens. Além disso, apenas dois professores orientaram mais de um trabalho no período sobre feminismo.

Se o gênero dos orientadores não é determinante para as pesquisas em Comunicação com centralidade em questões feministas, o gênero de quem pesquisa é. A partir do corpus mapeado, a imensa maioria é mulher, como é possível ver no gráfico abaixo (Figura 3):

Figura 3: Pesquisadoras/es

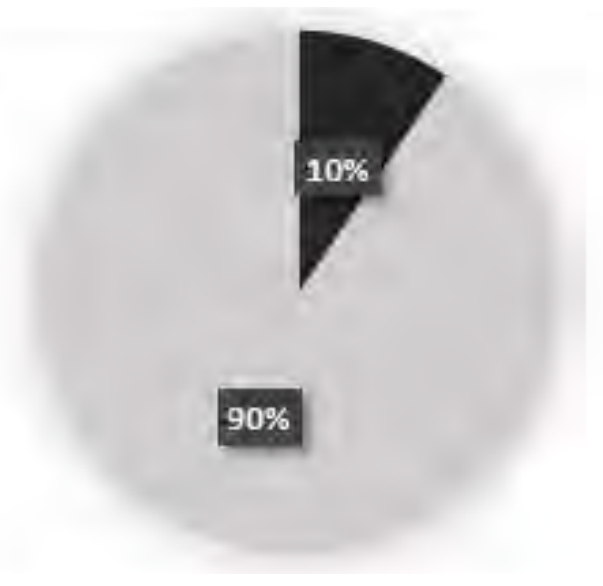

a Homens (2)

Muheres (19)

5 Ressaltamos aqui a questão da nossa área, já que existem outros programas, de outras áreas que contam com linhas de pesquisa sobre gênero ou gênero e feminismo. Também destacamos o Programa de Pós-Graduação em Estudos Interdisciplinares sobre Mulheres, Gênero e Feminismo, criado em 2006 na UFBA, que já conta com uma extensa produção, apesar de não termos encontrado trabalhos que problematizem essas questões a partir da Comunicação. 
Nem todos os trabalhos defendidos nesse período problematizam diretamente a noção de feminismo. Alguns desses trabalhos trazem a discussão feminista para contribuir com alguns argumentos (sobre gênero, sociedade, relações com a imprensa) de forma suficientemente importante a ponto de ser citado no resumo. Ao todo, 14 trabalhos trazem o feminismo como elemento fundamental presente na problemática da pesquisa, outros oito trabalhos usam o feminismo (teorias e estudos) para tensionar categorias, ou problemas de pesquisa levantados.

Entre os meios estudados, há uma maioria de trabalhos que parte do cinema (6), todos eles analisando filmes específicos que, em sua maioria, tratam de questões relativas à representatividade da mulher. Em seguida, os trabalhos que partem da internet (6) se dividem em conteúdos e espaços variados, como sites de rede social (3), fóruns de discussão (1), blogs (1), ferramentas educacionais (1). As revistas também merecem destaque, sendo objeto de 5 trabalhos. A maioria parte das revistas femininas (4) e apenas um analisa conteúdo de revistas semanais de referência. Os meios estudados nos trabalhos que compõem o corpus podem ser vistos no gráfico abaixo (Figura 4):

Figura 4: Meios estudados ${ }^{6}$

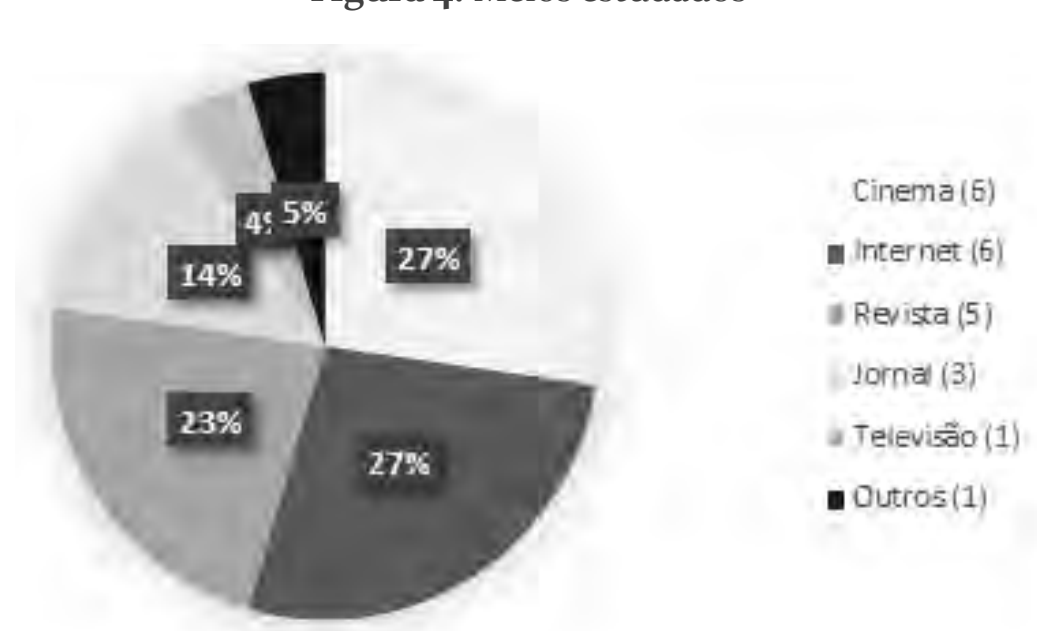

O cinema e seus produtos audiovisuais foram a principal motivação em seis trabalhos (Muzy, 2012; Paiva, 2014, Araújo, 2015; Dantas, 2015; Leite, 2015; Vasconcelos, 2015), a internet, seja através de blogs, redes sociais digitais ou fóruns de discussão, foi o ponto de onde parte a análise de seis trabalhos (Vieira, 2012; Batista, 2014; Oliveira, 2014; Paz, 2015; Tomazetti, 2015; Medeiros, 2015). O conteúdo de revistas foi o objeto de análise em cinco trabalhos: as revistas femininas em quatro (Portilho, 2010; Lôbo, 2015, Pontes, 2015; Medeiros, 2015), e um se dedicou a revistas semanais (Costa, 2015). Os jornais impressos foram os meios analisados em três trabalhos (Luz, 2014; Lemos, 2014; Fernandes, 2015), e a televisão em um trabalho (Andrade, 2011). Uma dissertação trouxe produtos de múltiplos meios, impressos e digitais, até mesmo pinturas e ilustrações com valor histórico (Souza, 2010).

6 Um trabalho analisa revistas femininas e blogs, por isso a soma dá 22. O item "outros" se refere a cartazes, quadros, pinturas e peças publicitárias. 
$\mathrm{Na}$ pesquisa também contabilizamos quais foram as autoras(es) mais utilizadas(os) durante o desenvolvimento dos trabalhos para as discussões sobre feminismo e relações de gênero. Em cada trabalho, destacamos as três mais citadas (Figura 5).

Figura 5: Autoras(es) mais citadas

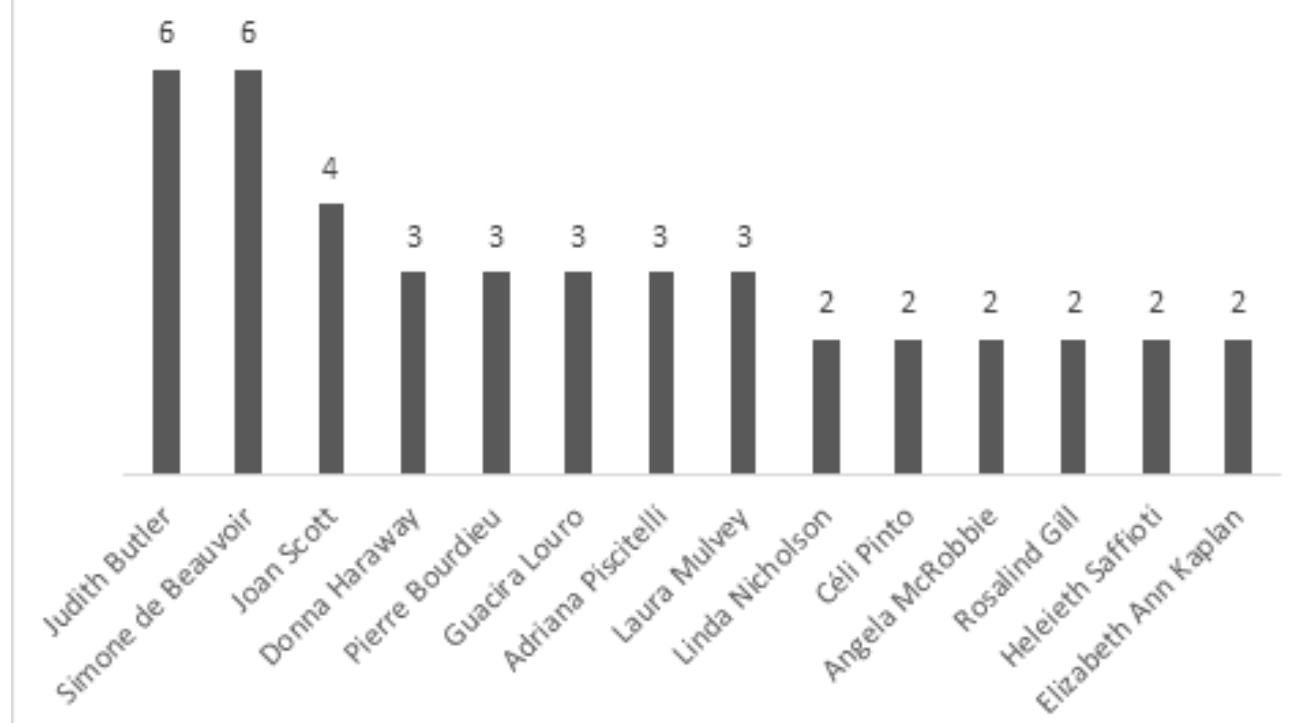

As duas autoras mais utilizadas são Judith Butler, principalmente para conceituar gênero a partir da perspectiva pós-estruturalista, e Simone de Beauvoir, e a obra O Segundo Sexo, para discutir desigualdade de gênero. Em seguida, aparece a historiadora Joan Scott e o artigo (traduzido para português) em que sugere a utilização de gênero como categoria analítica, Donna Haraway, a partir dos questionamentos sobre desigualdade de gênero nas ciências. Laura Mulvey e Elizabeth Ann Kaplan foram as mais utilizadas nas pesquisas sobre cinema, principalmente pelos trabalhos em que analisam, numa perspectiva feminista, a produção hollywoodiana. As autoras Angela McRobbie e Rosalind Gill, que trabalham na perspectiva dos Estudos Culturais, aparecem nas produções que propõem o conceito de pós-feminismo para entender a contemporaneidade. Mais citado em três trabalhos, Pierre Bourdieu é evocado para trabalhar as questões de desigualdade e violência simbólica a partir dos resultados da pesquisa etnográfica, das décadas de 50 e 6o, sobre a sociedade Cabila.

As estudiosas brasileiras mais citadas são Heleieth Saffioti, Céli Pinto e Guacira Louro. Saffioti, socióloga marxista, defende a importância do conceito de patriarcado até mesmo sobre o conceito de gênero. Pinto é professora titular do departamento de História da UFRGS e sua obra "Uma história do feminismo no Brasil" é uma das mais citadas para contextualizar o feminismo brasileiro. Uma das fundadoras do Grupo de Estudos de Educação e Relações de Gênero, Guacira Louro tem uma extensa produção sobre gênero, sexualidade e Estudos Queer. A antropóloga Adriana Piscitelli, nascida na argentina, mas que fez carreira no Brasil, pesquisadora da Universidade Estadual de Campinas, no Núcleo de Estudos de Gênero-PAGU, é citada para falar sobre interseccionalidade, além dos trabalhos que trazem sua conceituação de gênero. 
Muito da produção da Comunicação sobre feminismo parte de uma espécie de denúncia, de apontar como os meios de comunicação representam a mulher e apresentam os papéis relativos a gênero. Escosteguy e Messa (2008, p.22) já apontavam as questões relativas às representações midiáticas como um dos temas mais recorrentes, principalmente no período de 2000 a 2002. Mantendo essa tendência, a maior parte dos trabalhos, 14 deles, partiram da análise de como as mulheres, ou grupos de mulheres (mulheres negras, mulheres nordestinas, mulheres brasileiras), são representadas em produtos midiáticos (Portilho, 2010; Souza, 2010, Andrade, 2011, Muzy, 2012; Batista, 2014; Luz, 2014; Oliveira, 2014; Paiva, 2014; Araújo, 2015; Costa, 2015; Fernandes, 2015; Medeiros, 2015; Pontes, 2015; Vasconcelos, 2015), articulando diretamente com questões identitárias, ou abordando questões referentes a papéis de gênero. Um dos trabalhos traz a questão da mulher por trás das discussões sobre a representação do aborto durante a cobertura das eleições presidenciais de 2010 em jornais impressos (Lemos, 2014).

Duas teses (Vieira, 2012; Paz, 2015) e duas dissertações (Batista, 2014; Tomazetti, 2015) falaram do feminismo a partir de seus múltiplos movimentos e/ou questões transformadoras a partir de sua militância. A Marcha das Vadias, movimento social autogestionário que se articula através da internet para ações off-line, foi o objeto de dois desses trabalhos (Batista, 2014; Tomazetti, 2015). Além disso, as possibilidades que as tecnologias de informação e comunicação, especialmente os sites de redes sociais, tem para o movimento feminista, principalmente no que diz respeito ao combate à violência contra mulheres, foi abordado a partir de uma pesquisa-ação (Vieira, 20112). Já Paz (2015) partiu de coletivos feministas ligados à comunidade do movimento pelo software livre e procurou entender o lugar que esses coletivos ocupam no movimento e sua militância.

\section{Para além da denúncia}

Dentro do corpus analisado, o que mais ficou evidente é que grande parte dos pesquisadores utiliza o feminismo como maneira de contextualizar as desigualdades e/ou o tempo, como é o caso Portilho (2010) ao analisar as questões de representação da revista Claudia na década de 1960 que descreve a época como de "efervescência feminista", ou ainda Paiva (2014) e Araújo (2015) que ancoram suas análises a partir da história de desenvolvimento do feminismo.

Alguns trabalhos usam essa contextualização até mesmo de forma superficial, evocando o feminismo para falar de representação, mas sem entrar de fato nesse campo de conhecimento. Nesses casos, é tratado muitas vezes de forma difusa, como alerta Matos (2008), não só usando as ideias sem um esforço teórico em conceitua-las, mas muitas vezes usando teorias incompatíveis acrescidas de "gênero" ou "feminismo". Isso também foi visto em parcela dos trabalhos que se propôs a utilizar o feminismo como uma maneira de tensionar categorias ou problemas: foi trazido de forma genérica, 
o que pode gerar uma série de equívocos dada a pluralidade de perspectivas que o compõe.

Entre os trabalhos que chegam a problematizar o feminismo, há os que o tratam como conceito, e/ou movimento social e/ou pensando nos seus sujeitos. Costa (2015), por exemplo, a partir da análise de reportagens de revistas semanais de referência, pensa a construção da ideia de "mulher poderosa" e o estereótipo que vem com o que chama "novo tipo de feminismo". Já a tese de Lôbo (2015) evoca a teoria política feminista para analisar a construção da ideia de equilíbrio entre "vida e carreira" em três revistas femininas mensais, discutindo, entre outros temas, a questão dos cuidados e a distinção entre público e privado.

Leite (2015) faz uma análise a partir do que chama de "devir feminista" no cinema, que seriam produções que deslocam o olhar falocêntrico para uma mirada própria dos sujeitos. A partir desse esforço para repensar o conceito, a autora olha para diferentes produções audiovisuais, do gênero pornográfico ao documentário. Dantas (2015) também trabalha o feminismo a partir do cinema, mas parte do chamado "cinema de mulheres" para problematizar a perspectiva da autoria feminina como processo de subjetivação política do corpo, inclusive situando-os a partir de uma ruptura com binarismo de gênero e questionando o próprio sujeito do feminismo.

Batista (2014) articula a tríade feminismo - consumo - mídia para falar de uma nova configuração do feminismo a partir da experiência da Marcha das Vadias. Da mesma forma Tomazetti (2015) parte da identificação de sentidos do feminismo a partir das práticas de um grupo da Marcha das Vadias e identifica não só o processo de construção de uma identidade coletiva, mas como essa identidade se desenvolve a partir da experiência do feminismo na internet.

Ainda que alguns dos trabalhos citados tratem do feminismo de forma mais ampla, sem um "comprometimento" com alguma corrente teórica específica, são uma grande contribuição não só por repensar o feminismo na contemporaneidade, mas por fazerem aproximações importantes com o campo da comunicação, evidenciando relações que vão além da denúncia. Afinal, como lembra Olesen (1975, p.1-2), “a raiva não é suficiente”, é preciso avançar e gerar uma "sabedoria incisiva para modelar, direcionar e aproveitar a paixão em benefício de reparar grandes problemas encontrados".

Apontar as desigualdades geradas nos mais diversos meios de comunicação é importante, mas é mister que essas áreas - comunicação e feminismo - se encontrem também para gerar novos conhecimentos transformadores sobre si e sobre o mundo.

\section{Referências}

BRUNDSON, Charlotte. (1996). A thief in the night: stories offeminism in the 1970s at CCCS. In: MORLEY, D.. CHEN, K.H., HALL, S. Critical dialogues in cultural studies. London: Routeledge. 
CORUJA, Paula. (2017). Expressões do(s) feminismo(s): discussões do público com a youtuber Jout Jout. Dissertação (Mestrado em Comunicação e Informação) Programa de Pós-Graduação em Comunicação e Informação, Universidade Federal do Rio Grande do Sul. Porto Alegre.

ESCOSTEGUY, Ana C. (org.). (2008). Comunicação e gênero. A aventura da pesquisa. Porto Alegre: EDIPCRS.

ESCOSTEGUY, Ana C. (2001). Os estudos culturais. In: HOHLFELDT, Antonio; MARTINO, Luiz C.; FRANÇA, Vera Veiga (org.). Teorias da Comunicação: conceitos, escolas e tendências. Petrópolis, RJ: Vozes, p.151-170.

ESCOSTEGUY, Ana C. (2012). Pensando as relações entre mídia e gênero através de histórias pessoais: o caso brasileiro. Derecho a Comunicar, n. 4, p.174-176, Enero Abril.

GERAGHTY, Christine. (1998). Feminismo y consumo mediático. In: CURRAN, James, MORLEY, David, WALKERDINE, Valerie (Org.). Estudios culturales y comunicación: análisis, producción y consumo cultural de las políticas de identidad y el posmodernismo. Barcelona: Editora Paidós, p. 455 - 480.

HALL, Stuart. (2006). Da diáspora: Identidades e Mediações culturais. Belo Horizonte: Editora UFMG.

JOHN, Valquíria, COSTA, Felipe. (2014). Mulheres, identidade de gênero e sexualidade: problemáticas e desafios a partir do recorte por sexo. In: JACKS, Nilda. Meios e audiências 2: a consolidação dos estudos de recepção no Brasil. Porto Alegre: Editora Sulina.

MATOS, Marlise. (2008). Teorias de gênero ou teorias e gênero? Se e como os estudos de gênero e feministas se transformaram em um campo novo para as ciências. Revista Estudos Feministas, Florianópolis, v.16, n.2, p.333-357.

MESSA, Márcia R. (2008). Os estudos feministas de mídia: uma trajetória angloamericana In: ESCOSTEGUY, Ana C. (org.) Comunicação e gênero. A aventura da pesquisa. Porto Alegre: EDIPUCRS.

MORLEY, David. (1996). Televisión, audiencias y estudios culturales. Buenos Aires: Amorrortu editores.

MULVEY, Laura. (1999). Visual Pleasure and Narrative Cinema. In: BRAUDY, Leo, COHEN, Marshall (Eds). Film Theory and Criticism: Introductory Readings. New York: Oxford UP. 
MCROBBIE, Angela. (1998). More!: nuevas sexualidades em las revistas para chicas y mujeres. In: CURRAN, James, MORLEY, David, WALKERDINE, Valerie (Org.). Estudios culturales y comunicación: análisis, producción y consumo cultural de las políticas de identidad y el posmodernismo. Barcelona: Editora Paidós, p. 263 - 296.

OLESEN, Virginia (1975). Rage is not enough: scholarly feminism and research in women's health. In: OLESEN, V. Women and their health: research implications for a new era. Washington, DC: DHEW Publication.

RONSINI, V. SILVA, R. (2011). Mulheres e telenovela: a recepção pela perspectiva das relações de gênero. Revista da Associação Nacional dos Programas de Pós-Graduação em Comunicação - E-compós, Brasília, v.14, n.1, jan./abr.

RONSINI, V.; SANTOS, F.; FOLETTO, L; CASSOL, M. (2014). Introduzindo a questão das relações entre telenovelas, classe e gênero. In: RONSINI, V.; COGO, D.; REPOLL, J. (coord.) Estudos de Recepção Latino-Americanos: métodos e práticas. Bellaterra: InCom-UAB. p.173-194.

TOMAZETTI, Tainan, CORUJA, Paula. (2017). Relações de gênero: o desafio para além das binariedades, identidades e representações. In: JACKS, Nilda. Meios e audiências 3: a reconfiguração dos estudos de recepção e consumo midiático. Porto Alegre: Editora Sulina.

WOTTRICH, Laura H. (2017). "Não podemos deixar passar”: práticas de contestação da publicidade no início do século XXI. Tese (Doutorado em Comunicação e Informação) - Programa de Pós-Graduação em Comunicação e Informação, Universidade Federal do Rio Grande do Sul, Porto Alegre, 2017.

\section{CORPUS ANALISADO}

ANDRADE, Elizabeth R. N. (2011). A questão de gênero, meta do milênio da ONU, e sua invisibilidade na televisão brasileira contemporânea: análises de programas telejornalísticos, com ênfase na Rede Globo. Dissertação (Mestrado em Comunicação Social) - Programa de Pós-graduação em Comunicação, Universidade Anhembi Morumbi, São Paulo.

ARAUJO, Marcella G. (2015). Representações do feminino no cinema brasileiro de ficção: Mar de rosas, Um céu de estrelas e Trabalhar cansa. Dissertação (Mestrado em Multimeios) Programa de Pós-graduação em Multimeios, Universidade Estadual de Campinas, Campinas. 
BATISTA, Beatriz B. (2012). Por saias e causas justas: Feminismo, comunicação e consumo na Marcha das Vadias. Dissertação (Mestrado em Comunicação e Práticas de Consumo) - Programa de Pós-graduação em Comunicação e Práticas de Consumo, Escola Superior de Marketing e Propaganda, São Paulo.

COSTA, Tatiane C. L. (2015). A Mulher Poderosa: construções da vida bem-sucedida feminina no jornalismo brasileiro. Dissertação (Mestrado em Comunicação e Cultura) - Programa de Pós-graduação em Comunicação e Cultura, Universidade Federal do Rio Janeiro, Rio de Janeiro.

DANTAS, Daiany F. (2015). Corpos visíveis: matéria e performance no cinema de mulheres. Tese (Doutorado em Comunicação) - Programa de Pós-Graduação em Comunicação, Universidade Federal de Pernambuco, Recife.

FERNANDES, Danubia A. (2015). Mulher, Mulata e Migrante: modalidades representativas de uma tripla alteridade em jornais da Europa. Tese (Doutorado em Comunicação e Cultura) - Programa de Pós-graduação em Comunicação e Cultura, Universidade Federal do Rio Janeiro, Rio de Janeiro.

LEITE, Fernanda C. (2015). Cenários de gênero, sujeitos em trânsito: pelo devir feminista em audiovisuais contemporâneos. Tese (Doutorado em Comunicação) Programa de Pós-Graduação em Comunicação, Universidade Federal de Pernambuco, Recife.

LEMOS, Lis C. (2014). Não é pela vida das mulheres: o aborto nas eleições de 2010. Dissertação (Mestrado em Comunicação) - Programa de Pós-Graduação em Comunicação, Universidade Federal de Pernambuco, Recife.

LÔBO, Carolina C. (2015). Lugar de mulher: uma cartografia da construção discursiva da liberdade nas revistas femininas. Tese (Doutorado em Comunicação e Semiótica) - Programa de Pós-Graduação em Comunicação e Semiótica, Pontifícia Universidade Católica de São Paulo, São Paulo.

LUZ, Suelyn C. C. (2014). A participação das mulheres nos movimentos agroecológico e feminista e a contribuição do jornal Brasil de Fato. Dissertação (Mestrado em Comunicação) - Programa de Pós-graduação em Comunicação Midiática, Universidade Estadual Paulista “Júlio de Mesquita Filho”, Bauru.

MEDEIROS, Camila M. T. (2015). Jovens e Divas: construção do feminino na mídia contemporânea. Dissertação (Mestrado em Comunicação e Cultura) - Programa de Pós-graduação em Comunicação e Cultura, Universidade Federal do Rio Janeiro, Rio de Janeiro. 
MUZY, Luana S. (2012). Chicas del Montón: A representação de gênero no cinema de Pedro Almodóvar. Dissertação (Mestrado em Comunicação Social) - Programa de Pós-graduação em Comunicação Social, Pontifícia Universidade Católica do Rio de Janeiro, Rio de Janeiro.

OLIVEIRA, Rodrigo O. (2014). Garotas que jogam videogame: expressões de identidade e interações sobre cultura gamer no Facebook. Dissertação (Mestrado em Ciências da Comunicação) - Programa de Pós-graduação em Ciências da Comunicação, Universidade do Vale do Rio dos Sinos, São Leopoldo.

PAIVA, Carla C. S. (2014). Mulheres nordestinas, sujeitos ou objetos? Análise da representação feminina em quatro filmes brasileiros da década de oitenta. Tese (Doutoradoem Multimeios) Programa de Pós-graduaçãoem Multimeios, Universidade Estadual de Campinas, Campinas.

PAZ, Mônica S. D. (2015). Mulheres e Tecnologia: hackeando as relações de gênero na comunidade software livre do Brasil. Bahia. Tese (Doutorado em Comunicação e Cultura Contemporâneas) - Programa de Pós-graduação em Comunicação e Cultura Contemporâneas, Universidade Federal da Bahia, Salvador.

PONTES, Débora F. (2015). Como as revistas femininas brasileiras identificam as representações da sexualidade feminina: um estudo de caso sobre as revistas Lola, Nova e Marie Claire. Dissertação (Mestrado em Comunicação) - Programa de Pósgraduação em Comunicação Social, Universidade Federal de Juiz de Fora, Juiz de Fora.

PORTILHO, Raquel S. M. (2010). A Mulher e/em seu tempo: um estudo de Cláudia na década de 196o (1961-1969). Dissertação (Mestrado em Comunicação Social) - Programa de Pós-graduação em Comunicação Social, Universidade Federal Fluminense, Niterói.

SOUZA, Lisani A. (2010). Uma análise das imagens estereotipadas da mulher brasileira na mídia. Dissertação (Mestrado em Comunicação e Semiótica) - Programa de Pósgraduação em Comunicação e Semiótica, Pontifícia Universidade Católica de São Paulo, São Paulo.

TOMAZETTI, Tainan P. (2015). Movimentos sociais em rede e a construção de identidades: a Marcha das Vadias - SM e a experiência do feminismo em redes de comunicação. Dissertação (Mestrado em Comunicação) - Programa de Pós-graduação em Comunicação, Universidade Federal de Santa Maria, Santa Maria.

VASCONCELOS, Nayara. (2015). Metamorfoses de Phoenix: Representação feminina em fantasma do paraíso. Dissertação (Mestrado em Comunicação) - Programa de Pós-graduação em Comunicação, Universidade Anhembi Morumbi, São Paulo. 
VIEIRA, Vera F. (2010). Comunicação e feminismo: as possibilidades da era digital. Tese (Doutorado em Ciências da Comunicação) - Programa de Pós-graduação em Ciências da Comunicação, Universidade de São Paulo, São Paulo.

Recebido: 29.09.2017

Aceito: 29.05.2018 